\title{
CARDIAC PAIN WITH RECOVERY OF THE T WAVE
}

\author{
BY \\ TERENCE EAST AND SAMUEL ORAM \\ From the Cardiological Department, King's College Hospital \\ Received September 6, 1948
}

Surprisingly little attention has been paid to the possibility of a return to normal of cardiograms that have been thought to show the presence of cardiac infarction when the clinical picture was consistent with that accident having occurred. It is, of course, well known that very transient cardiographic changes, to be measured in minutes or hours, may accompany an anginal seizure. But the authors are concerned not with these cases, but only with those in which the changes persisted for days, weeks, or even months, but ultimately disappeared. The return to normal was so complete that from the inspection of the cardiogram alone, including unipolar exploration, it was impossible to tell that anything abnormal had ever occurred. Careful search of papers published in the past twenty years and more has failed to reveal any such similar investigation, although recently, as a result of experiments on dogs, the possibility has been hinted at by Bayley and Monte (1943) that perhaps in man similar temporary changes might be found, which were not due to an actual infarct.

In every case the account of the pain left no doubt that it was of cardiac origin, and only such cases as showed inversion of the T wave, in leads I or IV or both, or pathological inversion of the $T$ wave in lead III, were included in the series. In all cases standard leads and either IVR or CR 4, and IVF or CF 4, or both, were taken; and in all the patients encountered or followed up during the past two years unipolar leads were taken from the right arm (VR), left arm (VL), left foot (VF) and across the chest (V 1-6). The unipolar limb leads were augmented, using the Goldberger technique. Whenever the unipolar deflections obtained from the præcordium appeared inconveniently large in amplitude the fibre sensitivity was reduced by one-half, $(\mathrm{N} / 2)$, or even to one-third (N/3). Although in our records the amplitude of the $T$ wave is only one-half or one-third of the size of the usual deflection, the proportion of the height of this wave to that of the
QRS complex remains, of course, unaltered. Some patients were further explored in a manner suggested by the results obtained from the above leads. For example, when the lateral wall of the left ventricle was involved, leads were taken from intercostal spaces higher than those usually employed, and in some of the cases suggesting posterior cardiac infarction a deep epigastric lead was taken. In all, the 28 cases were cardiographed on 140 occasions.

\section{Selection of Cases and Frequency}

We had constantly in mind such other causes as might lead to temporary inversion of $T$ waves, and we took care to exclude these as far as possible. For example we excluded any patient in whom one might have suspected that digitalis was responsible for the $T$ wave changes. All records were taken with the patient recumbent. There was no question of any patient having drunk cold water just before his test. None was receiving adrenalin; and, although one was diabetic, it was thought that insulin did not influence the $T$ wave. One patient was myxodematous, but the changes in the $T$ wave were not characteristic of that disease: we are of opinion that it was not responsible for subsequent cardiographic changes. We excluded one patient with severe anæmia and two who were receiving desoxy-cortico-sterone acetate, for we did not consider that the changes in their $\mathrm{T}$ waves should find a place in this series. If there was any doubt concerning the presence of attacks of paroxysmal tachycardia, that case also was omitted. All the cases were adults, so the negative $T$ waves of childhood were excluded. There was no question of trauma to the chest wall or elsewhere.

In the twelve-year period 1936-47 inclusive, cardiograms were taken from 5593 patients, and of those 367 yielded curves considered diagnostic of cardiac infarction. Of the 367 cases, 232 were of the anterior type, 131 were posterior, and 4 were considered to show evidence of both. Of the 232 
anterior variety, 26 (11 per cent) were found that reverted to normal; but of the 131 posterior, only 2 ( 1.5 per cent) could be found whose curves had done so. None of the 4 cases showing combined anterior and posterior infarction resumed a normal appearance.

It is seen that of the total number of 367 cases of cardiac infarction, 28 ( 8 per cent) eventually became normal, and that of these there was a striking preponderance of the anterior type. Of these 28 cases, 22 have cardiograms that have remained free from any pathological change whatever during the time we have kept them under observation.

\section{Clinical Details}

Of our 28 cases, 22 were men and 6 were women. The ages when the patients were first seen ranged from 39 to 77 , more than half of them being over the age of 50, and three were over 70 . The average age was 54 years.

Although the period during which the patients were observed was in one case only two months, we were fortunate to have seven of our patients under observation for more than eight years. On the average they were followed up for just over four years. A study was made, from a consideration of the history and the type of the pain experienced, to see whether any clinical feature might emerge that would suggest the temporary nature of the abnormality in the cardiogram; but none did. The diagnosis of angina pectoris or cardiac infarction had been made in every case before the cardiogram was taken, and the curve was thought at that time to be confirmatory. In ten cases the pain was experienced only whilst the patient was at rest, while in seven pain was only present on exertion. In the remaining eleven patients pain was present both at rest and on effort. The pain recurred subsequent to the initial attack in 23 of the 28 patients. It was a peculiar feature that in five patients, in spite of recurrent and apparently typical cardiac pain, which in each of the five cases lasted more than an hour, the cardiogram remained normal. We could find no correlation between the severity or duration of the pain and the degree of inversion of the $T$ wave. A persistently high blood pressure, the systolic being more than 160 or the diastolic greater than 95 or both, was present in 18 patients. In 9 it was normal and in one we have no record. Unfortunately we have insufficient information concerning serial white cell counts and sedimentation rates in this series to discuss their diagnostic value, but sometimes there was a slight degree of pyrexia, and the white cells and sedimentation rate were increased somewhat, although for the most part these were unchanged.

\section{CARDIOGRAMS}

Six facts emerged from inspection of the curves of this series. First, the anterior lesion was very much commoner than the posterior, much more so than with established infarction. Only 2 of the 28 cases were of the posterior type. Secondly, in every cardiogram showing an anterior lesion the $Q$ wave was either absent altogether, or, if present, was very small: In no case was the $Q$ wave in the lead or leads showing inversion of the $T$ wave significantly prolonged $(0.04 \mathrm{sec}$. or more $)$; in lead $I$ it did not exceed $1.0 \mathrm{~mm}$. in depth, and in lead IV $1.5 \mathrm{~mm}$. As a rule there was no $Q$ wave (see Table). Thirdly, in the posterior type, unlike in the anterior, a $Q$ wave may appear which is pathologically deep and wide in leads II, III, and VF, and yet ultimately this may revert to normal dimensions or disappear (Fig. 5). Fourthly, significant displacement of the RS-T segment by the current of injury was only present in two cases (Fig. 8) and was actually less than $2 \mathrm{~mm}$. As the records were taken in several of our cases at all stages of the event, even during the paroxysm of pain, the absence of this current was surprising and will be commented on later. Fifthly, it was noted that once the cardiogram had reverted to normal the tendency was for it to remain so, and only in an unexpectedly small number did it deteriorate again. Thus, of the 28 cases that reverted to normal, 22 were still without pathological change when we last saw them. Of the other 6 , one showed digitalis effect only, one showed the picture of left ventricular predominance, and in three of the remaining four that subsequently deteriorated, the abnormal feature was nothing more than an isoelectric $T$ wave in lead $I$. The cardiogram of the fourth patient, after reverting to normal several times, finally persisted as a curve of cardiac infarction (Fig. 10). Finally, on several occasions when our records were taken, the patient was experiencing a severe attack of pain, but they did not necessarily show inversion of the $T$ wave at that moment, although this abnormality subsequently appeared.

\section{Prognosis}

This is beyond doubt much better than that usually given for cardiac infarction. Of the 28 cases only 3 are dead and one of these (Case 1) died of septicæmia. Autopsy was performed and the findings are given below. No details are known of the mode of death of the other two, but one lived for 8 years following the appearance of his abnormal record and was 70 at the time of his death; the other died at the age of 79 , his abnormal record having appeared when he was 75 .

The exact length of time taken for the abnormal curve to revert to normal is difficult to assess 
accurately unless records are taken at very frequent intervals. The times estimated for the curves to become normal are thus necessarily maximal. The shortest time was two days and the longest was three years and eight months, the average being 33 weeks. Of the 28 cases, 20 were active when last seen and, of these, 15 were quite free from pain. Three had experienced very slight pain which was inframammary in type and not of cardiac origin. Two patients had slight cardiac pain, with but little limitation of activity. Three others were free from pain but restricted by dyspnœa. Two were considerably hampered by pain: as already stated, three had died.

\section{Morbid ANATOMY}

As mentioned above, the outlook in these patients would appear to be so good that opportunities for autopsy are few. The only one of this series (Case 1) that came to necropsy died as a result of obscure septicæmia. There was some excess of fat in the epicardium and the heart was enlarged and dilated, particularly on the right side. The myocardium was soft and flabby. Two doubtful pale areas of scarring, superficial and just visible to the naked eye, were present a little distance from the tip of the anterior wall of the left ventricle. In spite of careful search, section of the heart failed to reveal any other abnormal areas. The main coronary vessels were quite patent and quite free from atheroma. The valves and pericardium were normal. Early changes of right-sided heart failure were present in the lungs, liver, spleen, and kidneys.

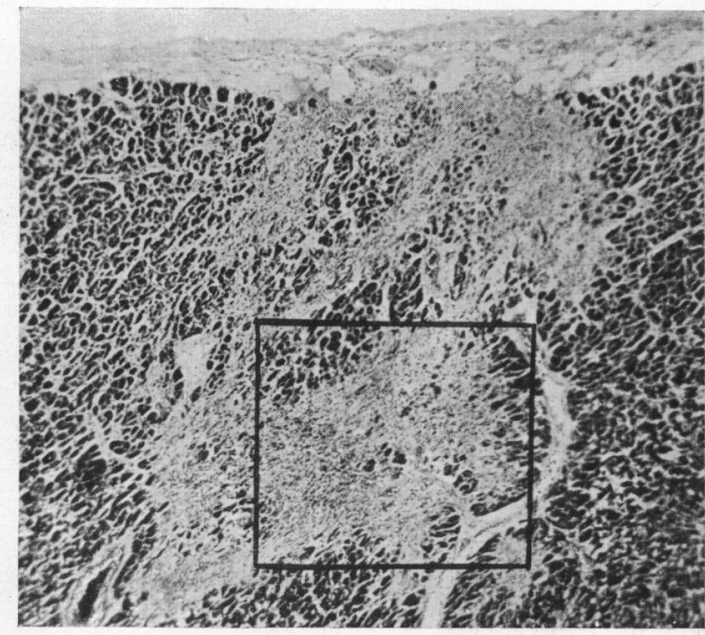

A
Microscopically, the small sub-epicardial area sectioned consisted of a fairly well localized patch of fibrosis. Microscopic branches of the coronary vessels seen were healthy (Fig. 1).

\section{Illustrative Cases}

Unfortunately, space does not permit us to include full clinical and cardiographic details of all 28 cases, so we have listed the more important features (see Table) and chosen to illustrate from our series only such examples as show features worthy of particular comment. This has necessitated the omission of a number of inlustrations showing widespread and well-marked abnormalities, but of similar form. Ten cases are presented: the first is one in which autopsy was performed; the second is a typical anterior lesion; the third is also anterior and shows how widespread abnormalities in the unipolar præcordial leads can revert to normal; the fourth is one of our two posterior lesions in which the cardiogram recovered; the fifth is an example of anterior type where only $\mathrm{T} 4$ was inverted and not $\mathrm{T} 1$; the sixth showed inversion of $\mathrm{T} 1$ but not of $\mathrm{T} 4$; the seventh is presented because it is one of the two in which any RS-T segment displacement occurred; the eighth case, although presenting a seemingly established picture, showed that by inhalation of amyl nitrite it was possible to elevate an inverted $\mathrm{T} 1$ and $\mathrm{T} 2$, although these two waves became again inverted after five hours; the ninth case shows spontaneous inversion of $\mathrm{T} 1$ and $\mathrm{T} 4$, often but not always associated with attacks of cardiac pain; the tenth case is.

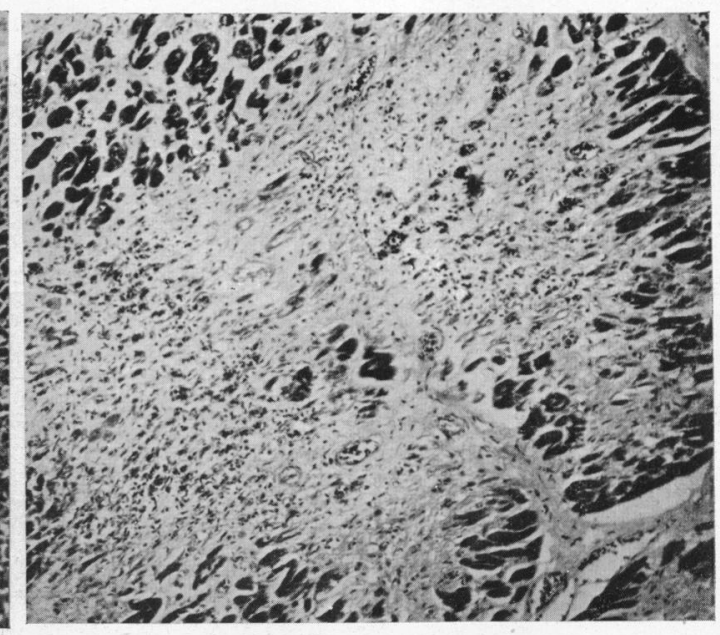

B

FIG. 1.-Case 1. The larger of two very small pale areas just visible beneath the epicardium. It consists of a well localized patch of replacement fibrosis. The branches of the coronary vessels are quite healthy. (A) Magnification $\times 35$. (B) Magnification $\times 105$. 


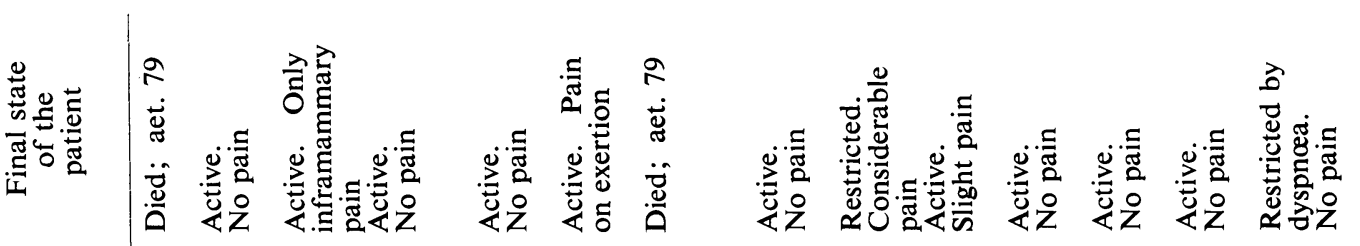

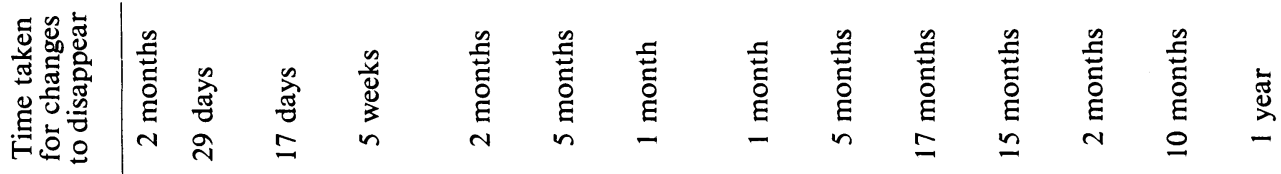

旁

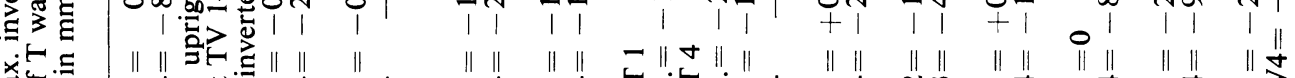

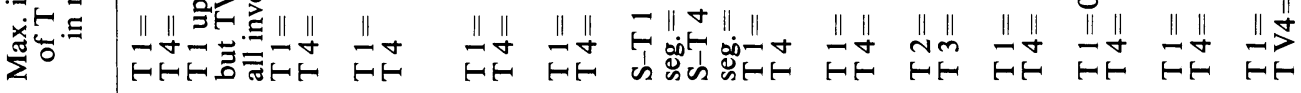

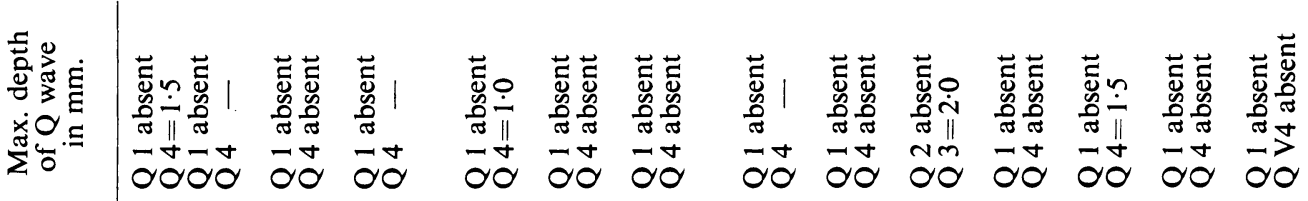

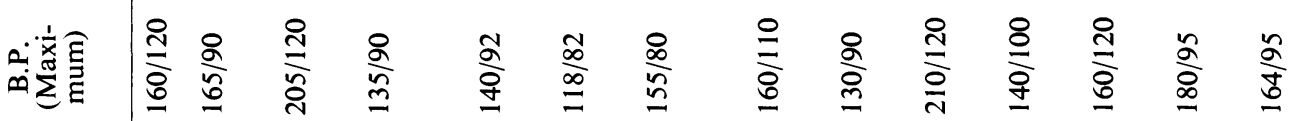

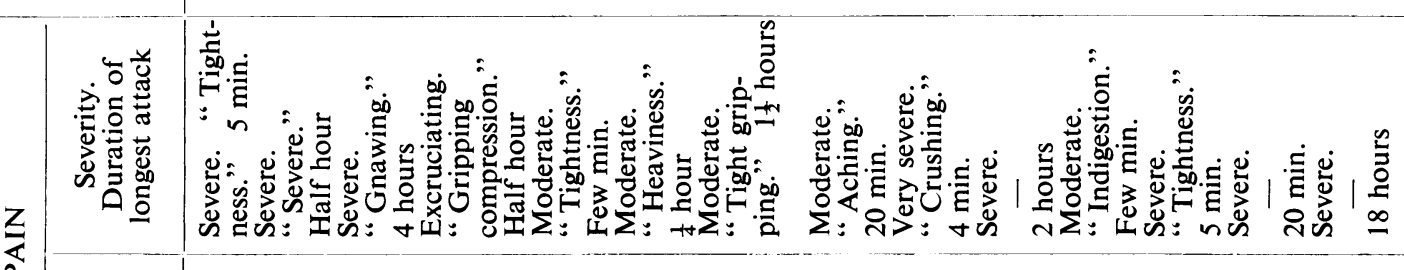

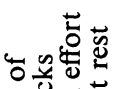

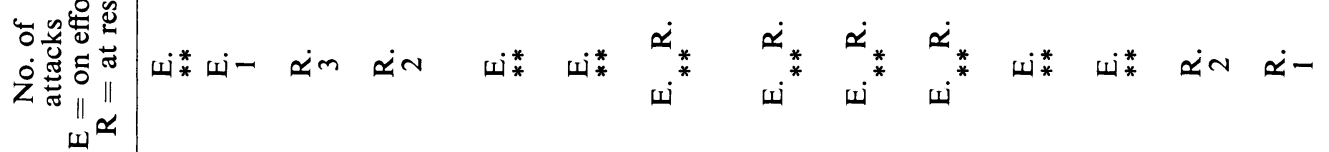

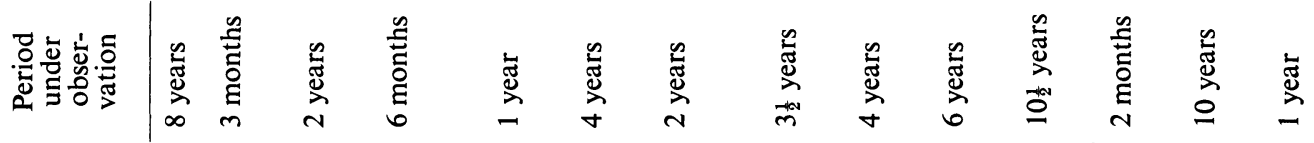

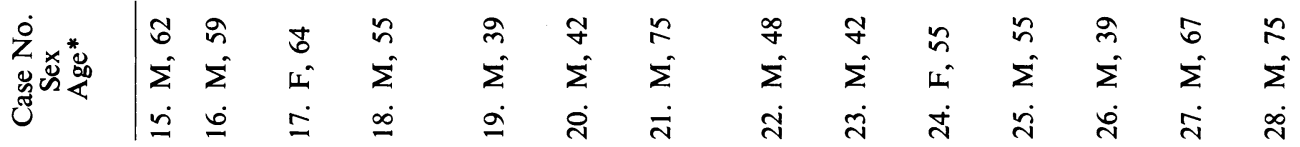


included because it is the only example we have met where the $T$ wave in lead CF 4 varied, alternately being upright and inverted from beat to beat.

Case 1 (Fig. 1 and 2). Man, aged 43. In July 1946 typical symptoms of failure of the left ventricle first appeared. Dyspnca on effort was soon followed by attacks of severe nocturnal dyspnœa. A few weeks later he complained of a choking sensation, as though he were being strangled, accompanied by a dull pain in the left chest. This pain inverted, and inversion of $\mathrm{T} 4$ persisted. No $Q$ waves were present. Further cardiograms taken on $15 / 11 / 46$ and $2 / 12 / 46$ showed some improvement, and by 28/1/47 normal rhythm was present, $\mathrm{T} 1$ was flat and $\mathrm{T} 4$ was almost so.

Comment. This case is presented in some detail as we were fortunate enough to obtain a necropsy owing to the patient's death from septicæmia. Although the last cardiogram (28/1/47) before his death on 26/2/47 was not normal, it showed considerable improvement over the one taken on

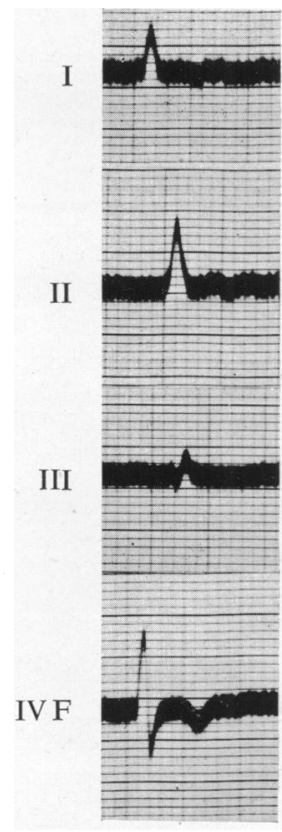

$29 / 10 / 46$

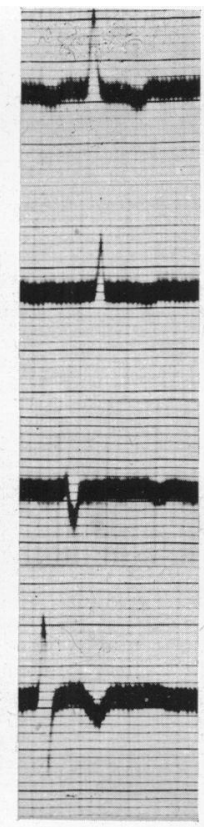

$6 / 11 / 46$

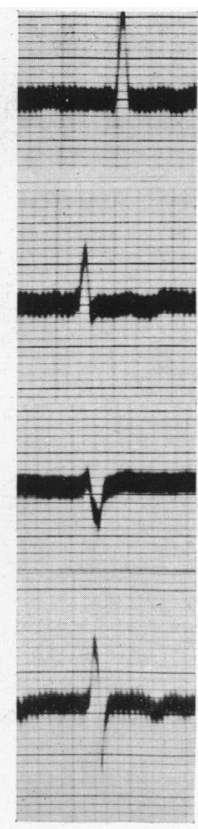

$15 / 11 / 46$

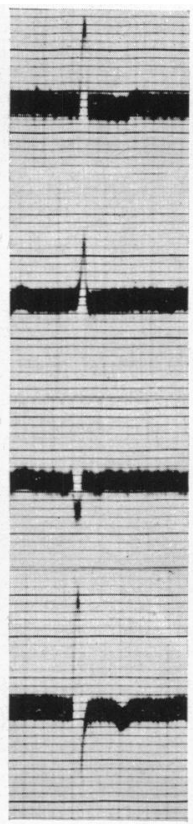

$2 / 12 / 46$

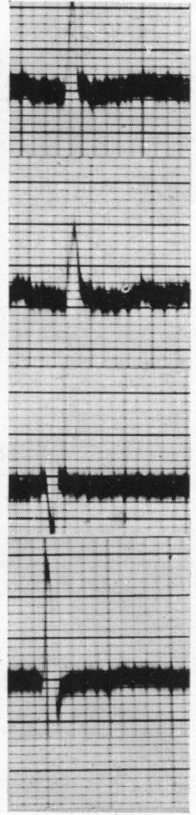

$28 / 1 / 47$

Fig. 2.-Case 1. Cardiogram suggesting anterior cardiac infarction, and showing improvement prior to death from septicæmia. Auricular fibrillation.

was at first only brought on by exertion such as walking and always brought him to a standstill. It lasted for fifteen to twenty minutes, never longer, and did not radiate.

During his stay in hospital several of these attacks of pain occurred whilst he was asleep, and awakened him. Auricular fibrillation was present intermittently, and, although on admission his blood pressure was $160 / 100$, it fell during his stay to $130 / 90$ and, just before death, to $80 / 48$.

Whilst in hospital he developed a fatal septicæmia, the origin of which was never discovered.

On 29/10/46 his cardiogram confirmed that auricular fibrillation was present. T 1 and T 2 were flat and T 4F was sharply inverted. By 6/11/46, T 1 was
$6 / 11 / 46$, which was suggestive of anterior cardiac infarction. The inversion of $\mathrm{T} 1$ and $\mathrm{T} 4 \mathrm{had}$ practically disappeared within the last three months. Naked eye and microscopical appearances have been described and illustrated above (Fig. 1). Notwithstanding the cardiographic appearances, the degree of localized cardiac muscle destruction was minimal. We feel here that, had the patient not succumbed to incidental disease, such a trivial lesion would hardly have impaired a very good chance of complete recovery, particularly in the absence of coronary atheroma.

Case 2 (Fig. 3). Man, aged 53. The patient was quite well until $23 / 3 / 38$ when he suddenly experi- 


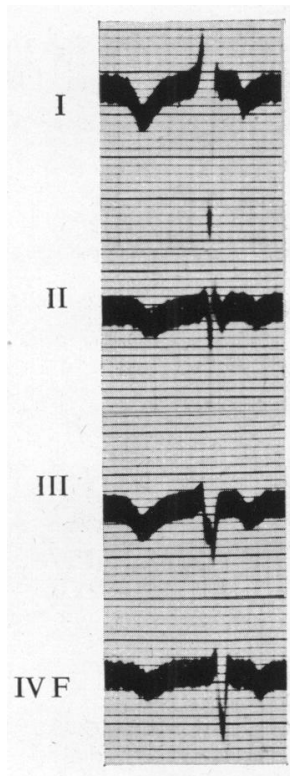

$30 / 3 / 38$

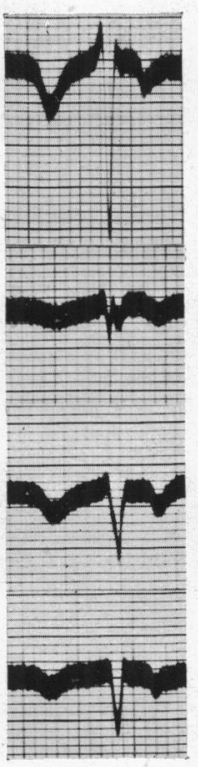

$5 / 4 / 38$

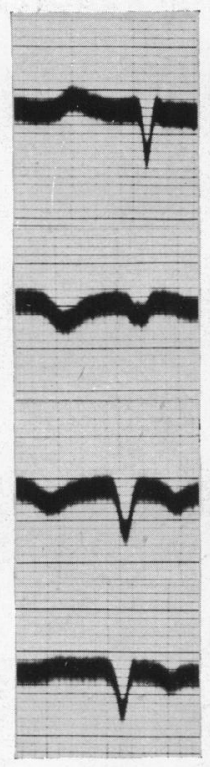

$23 / 5 / 38$

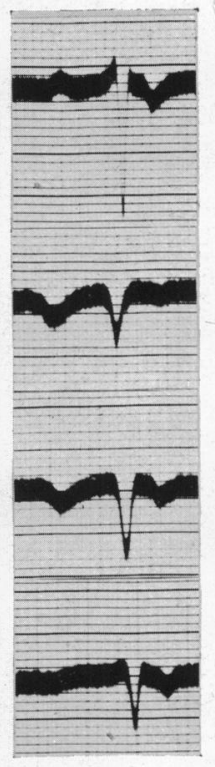

$3 / 11 / 41$

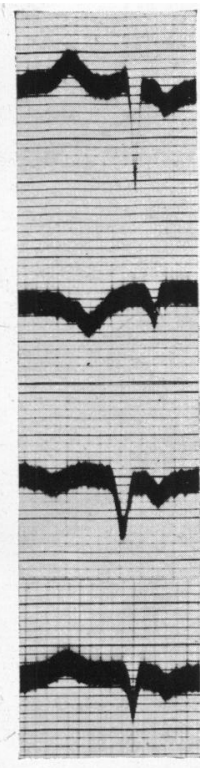

$24 / 3 / 48$

FIG. 3.-Case 2. Recovery of abnormal cardiogram suggesting anterior infarction but with no $Q$ waves.

enced a violent substernal pain whilst he was at rest. Subsequently this type of pain occurred on exertion, the attacks lasting five to ten minutes and being relieved by rest. Whenever the pain was particularly severe it radiated down his left arm. When seen six days after his first attack of pain, his blood pressure was $118 / 95$, gallop rhythm was present, and he was found to have diabetes.

His cardiogram on $30 / 3 / 38$ was taken during an attack of pain and showed inversion of $\mathrm{T} 1$ and $\mathrm{T} 4 \mathrm{~F}$ and elevation of $T 3$. The $R$ waves were of low voltage but no $Q$ waves were present. When repeated on 5/4/38 T 1 had become flat and T 4 had become $2 \mathrm{~mm}$. less inverted. By 23/5/38 the gallop rhythm was still faintly audible. His cardiogram was virtually the same.

When seen on $13 / 6 / 38$ he was still experiencing occasional pain, the gallop rhythm was gone, and he could walk a mile or so before becoming breathless. His B.P. was $105 / 65$. He was seen again on $3 / 11 / 41$ and the cardiogram was taken just as an attack of pain had ceased. To our surprise the record was quite normal and even the $R$ wave amplitude had increased. When seen on 29/5/46 he was experiencing rather vague " neuritic" præcordial pains on walking, there were no abnormal physical signs, his diabetes was controlled by diet alone and his cardiogram was still normal.

He was seen again on 24/3/48 and he had been keeping symptom-free, showed no abnormal physical signs, B.P. $140 / 90$, and the cardiogram in the standard leads, unipolar limb and præcordial leads, was quite normal.

Comment. Typical cardiac pain was present, coming on at first at rest and later on exertion also, in a moderate diabetic. His cardiogram was originally considered typical of anterior cardiac infarction, becoming normal before the attacks of pain had ceased. In fact, one taken immediately after a severe attack of pain was quite normal. Ten years from the first attack, his cardiogram is still normal. This case illustrates well how a normal cardiogram may be consistent with the presence of severe cardiac pain.

Case 3 (Fig. 4). Man, aged 48. At the beginning of April 1947 whilst the patient was at rest in a chair, he had a sudden attack of pain and numbness which began in the left arm and radiated up to his left shoulder and across the upper part of the sternum, where it became of frightening intensity and was associated with considerable dyspnœa. The chest pain was described as " pulling together, as though the left arm were being torn out." Much angor animi was present. He sweated profusely during the attack and his wife commented on his extreme pallor. The attack lasted twenty minutes and went off quite suddenly. During the next two hours he had two 

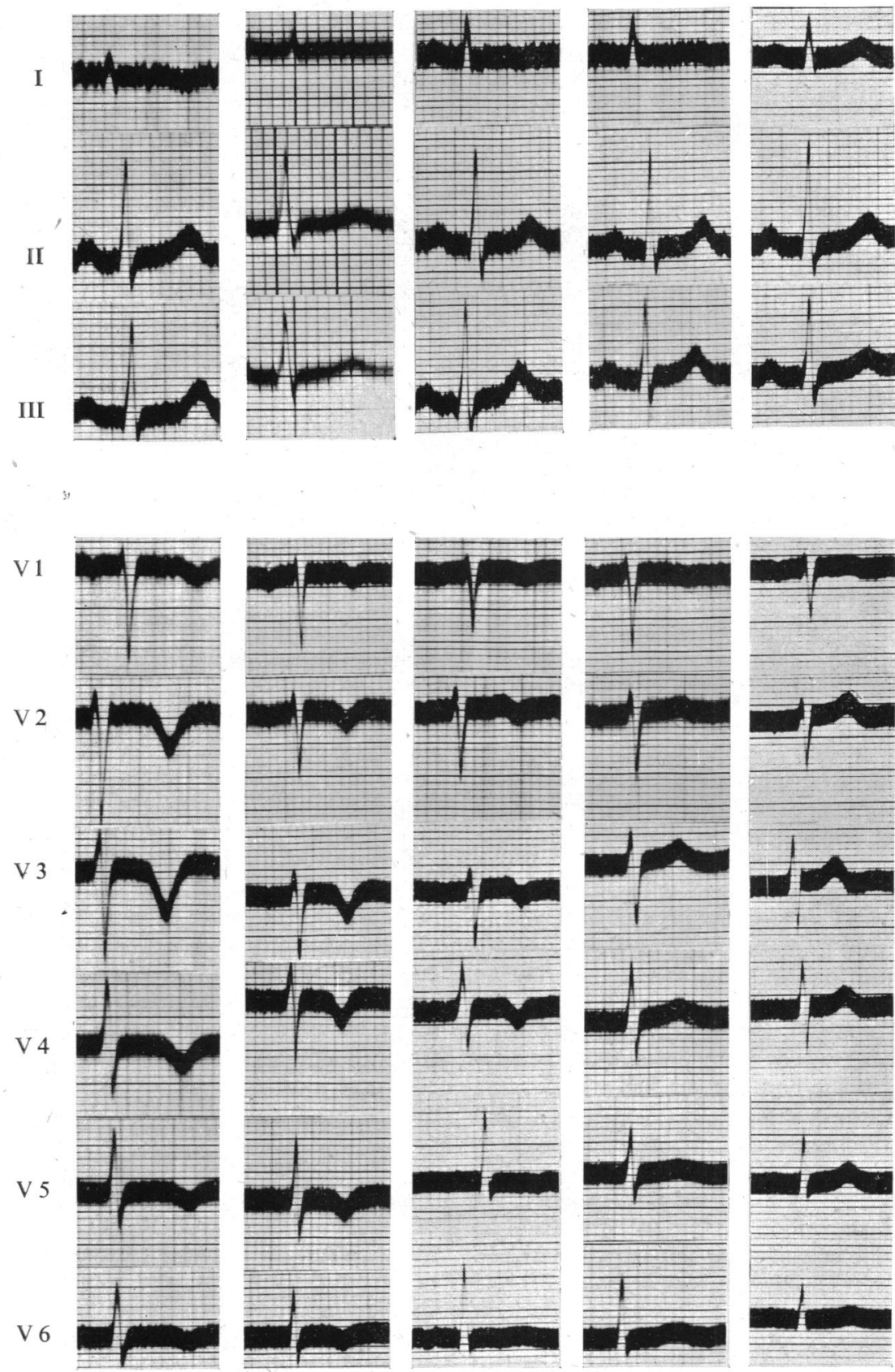

$23 / 4 / 47$

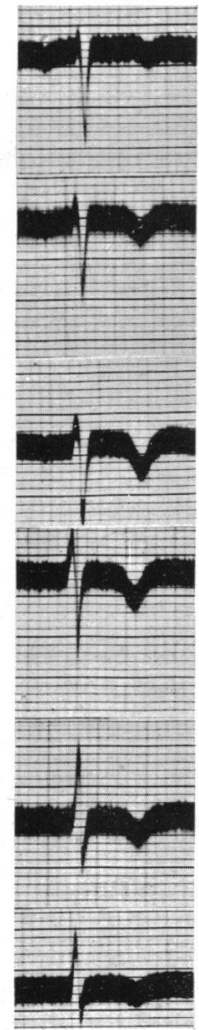

$28 / 4 / 47$

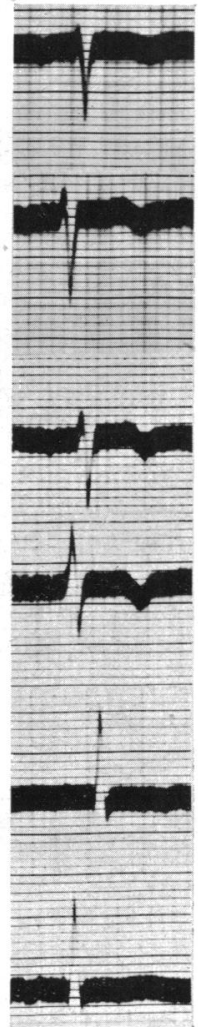

$13 / 5 / 47$

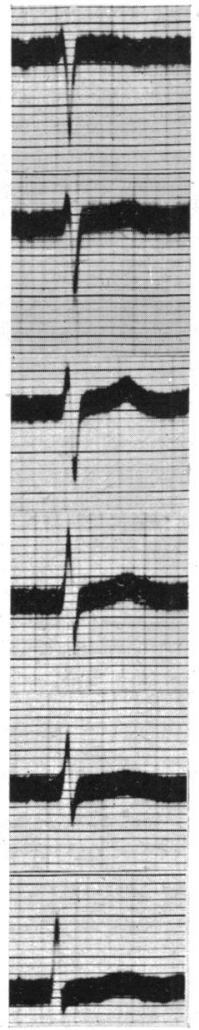

$28 / 5 / 47$

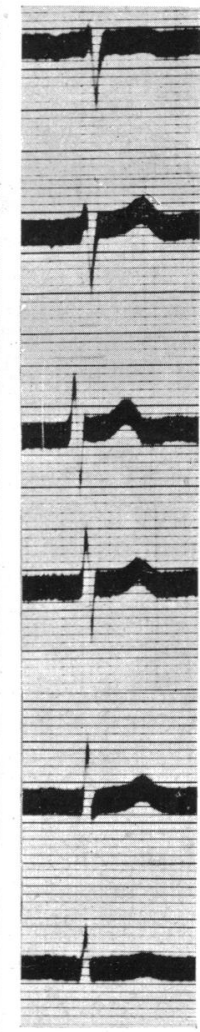

$4 / 5 / 48$

FIG. 4.-Case 3. Cardiogram suggests widespread anterior lesion, but without the presence of $Q$ waves. The record became normal within five weeks, and a year later was still so. $\quad$ lead fibre-sensitivity $=\mathrm{N} / 2$. 
similar, but less severe, episodes whilst in bed. A further attack came on whilst he was walking from work and the pain again started in the left arm, which felt heavy.

Clinical examination on $23 / 4 / 47$ revealed no abnormal physical signs, B.P. $130 / 90$, but the cardiogram taken the same day showed, in addition to slight inversion of $\mathrm{T} 1$ with a low voltage QRS, pathological $T$ inversion of all the unipolar præcordial leads, especially V2, V3, and V4, although no $\mathbf{Q}$ waves were present. The B.S.R. taken the next day was $4 \mathrm{~mm}$. in the first hour (Westergren) and a white cell count taken on 25/4/47 was 12,000 per c.mm. It was considered that the patient had had a coronary artery occlusion, but that although the ischæmic area was of great extent, it was not. transmural.

He was treated with anti-coagulant therapy.

No further pain occurred whilst he was in hospital and on the day of his discharge, $13 / 5 / 47$, the cardiogram showed that his præcordial $T$ waves had become less inverted, those of V 5 and $\mathrm{V} 6$ being flat. A fortnight later, on $28 / 5 / 47$, T 1 was just upright and V2-6 inclusive had become upright. He was last seen on 4/5/48 and he had been quite free from pain or disability of any sort for one year and his cardiogram, standard, unipolar limb and præcordial leads, was quite normal.

Comment. Cardiac pain of great severity was associated with cardiographic changes of extensive antero-lateral distribution without $\mathrm{Q}$ waves. These changes, together with the pain, disappeared within five weeks, and a year later, both clinically and cardiographically, the patient was quite normal. It is noteworthy that fever, leucocytosis, and increase in the sedimentation rate were inconspicuous.

Case 4 (Fig. 5). Man, aged 48. Whilst sitting at a desk at 10.30 p.m. on $14 / 7 / 44$ the patient experienced sudden intense, continuous, retrosternal pain, which lasted four hours ("like very severe indigestion, although much worse "). He also felt it in both arms, from elbow to thumb, and it caused him to sweat. His doctor found no abnormal physical signs, although he saw the patient a few hours later. The patient felt absolutely fit within two days and he was sent to hospital where a cardiogram, taken on $20 / 7 / 44$, only revealed a rather tall $P$ wave in lead II, although there was slight inversion of T III. However, in view of his story he was admitted to hospital, and further cardiograms were taken. Although no further pain occurred, the second record taken on $31 / 7 / 44$ showed the usual appearances of posterior cardiac infarction with deep inversion of T II and T III and prominent Q II and Q III. The cardiogram improved and by 18/9/44 it was quite normal.

When seen on $4 / 5 / 48$, nearly four years after his attack, he had been keeping very well indeed and was leading an active life, without any pain or other disability whatsoever. There were no abnormal physical signs, B.P. 120/75, and his cardiogram was still quite normal.

Comment. A single isolated attack of severe cardiac pain associated with a cardiographic appearance that, although at first was normal, showed a few days later the typical appearance of posterior infarction, including the presence of $Q$ waves. Even so, the cardiogram had recovered within two months.

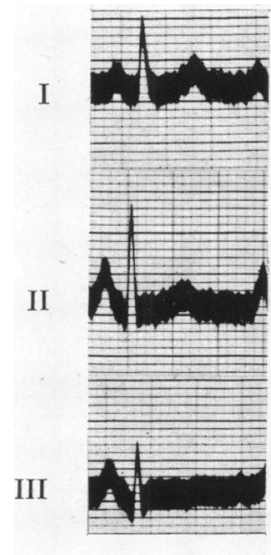

$20 / 7 / 44$

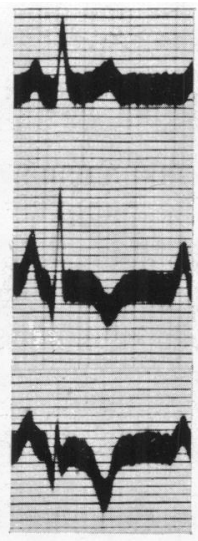

$31 / 7 / 44$

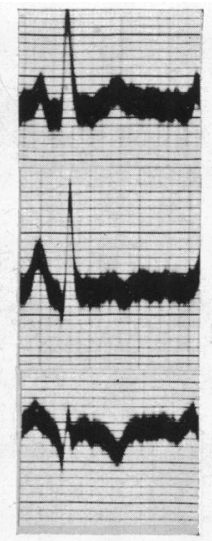

$13 / 8 / 44$

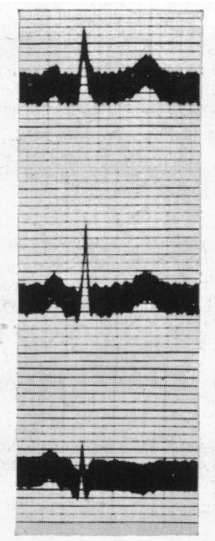

$18 / 9 / 44$

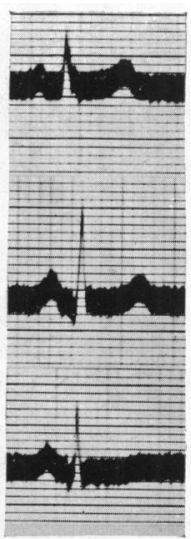

$4 / 5 / 48$

FIG. 5.-Case 4. A type of posterior lesion. The cardiogram recovered within two months, and both the patient and his record have remained normal for four years. 
The patient has remained quite fit and has had a normal record for four years. This case also is an example of cardiac pain being accompanied for a few days by a normal cardiogram which only subsequently assumed the appearance typical of infarction.

Case 5 (Fig. 6). Man, aged 66. This active fisherman was first seen by us nearly ten years ago and complained of three distinct attacks of severe præcordial oppression which radiated down the left arm. The first occurred on $8 / 8 / 38$, while he was pushing his boat down to the beach. The pain during the third attack lasted all day.

$\mathrm{He}$ was first seen on $5 / 9 / 38$. There were no abnormal physical signs apart from a very slight scoliosis and a trace of albumen in the urine, B.P. $130 / 78$. The cardiogram on that date showed $T 1$ to be rather low but upright, but deep inversion of $\mathrm{T} 4 \mathrm{~F}$ was present, although there were no $\mathrm{Q}$ waves. A record taken on 24/10/38 showed normal standard leads, but T 4F was only just upright. On 27/2/39 his cardiogram was quite normal with an upright $T$ in $4 F$ of good amplitude, and a $Q$ wave had appeared. The pressure had risen to 145/105.

A cardiogram on 23/5/39 was identical in appearance with that of $27 / 2 / 39$. The pressure had risen to $160 / 110$.
When last seen on 14/1/48 the blood pressure was $195 / 100$. The cardiogram, standard leads, CR 4, CF 4, unipolar limb and præcordial leads, was quite normal and he was leading a normal symptom-free life ; during the whole of the war his work had been particularly arduous.

Comment. This is an example of cardiac pain precipitated by severe exertion, accompanied by changes in lead 4F but without changes in lead $\mathrm{I}$. Within six months the curves had become normal and they have remained normal for nearly ten years and the patient has remained well. Lenègre and Chevalier (1946) have recently recorded 32 patients with such $T$ wave changes and concluded that provided the patient is more than twenty years of age, isolated inversion of T 4 is pathological and most often of coronary origin.

Case 6 (Fig. $7 A$ and B). Man, aged 43. When first seen on $3 / 5 / 45$ his history was that ten days previously he had felt ill and feverish for a day but did not go to bed. The next night he still felt unwell and woke at 11 p.m. with a nasty dull pain in the upper chest, which he described as being like a "sore trachea." He was restless during the pain, which lasted for several hours. The pain recurred, though less severely, at odd times during the next few days
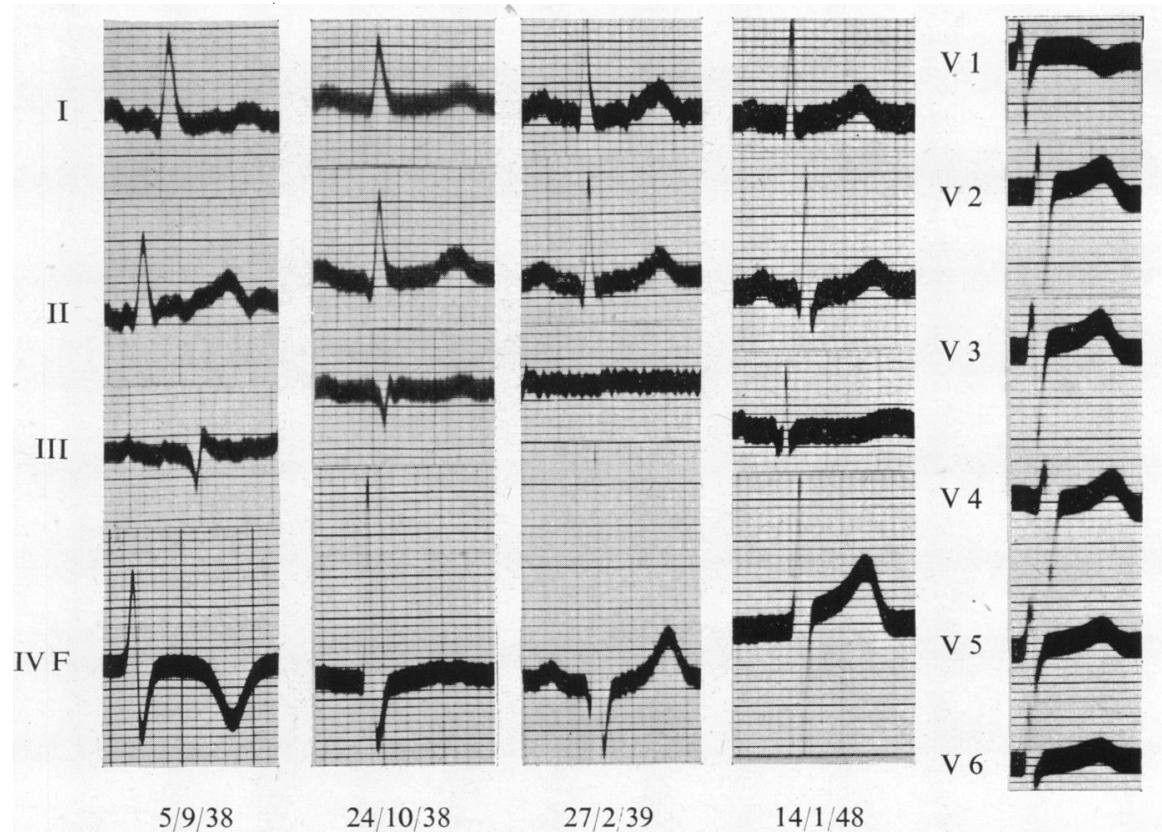

Fig. 6.-Case 5. An example cf inversion of $\mathrm{T} 4 \mathrm{~F}$ but with $\mathrm{T} 1$ remaining upright. Cardiographic recovery occurred within six months and has persisted for nearly ten years. $\mathrm{V}$ lead fibre-sensitivity $=\mathrm{N} / 2$. 


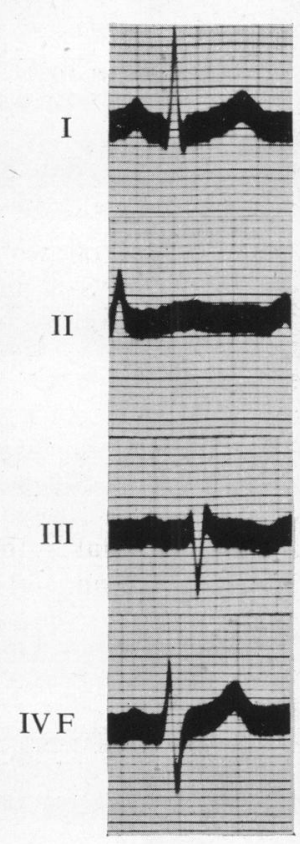

$3 / 5 / 45$

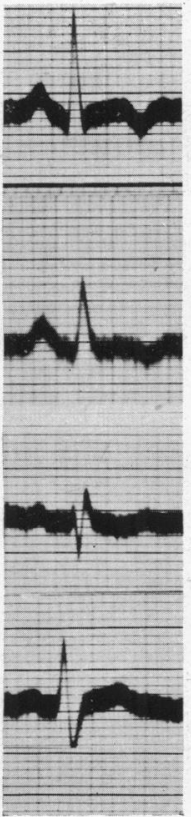

$8 / 8 / 46$

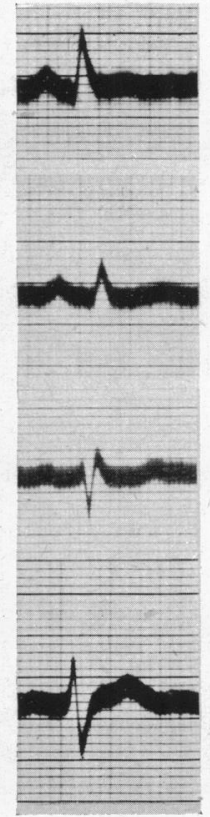

26/8/46

A

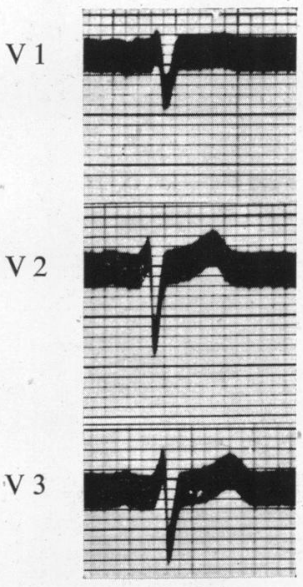

$20 / 4 / 48$

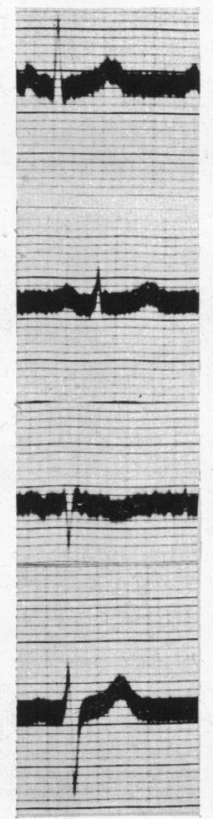

$5 / 11 / 46$

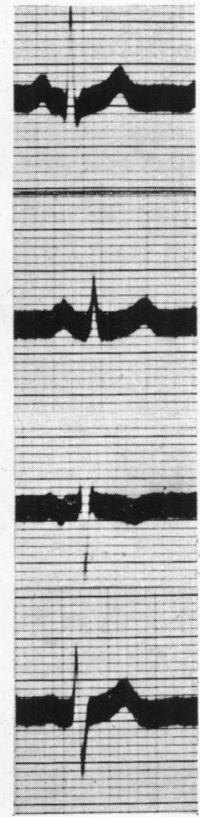

$20 / 4 / 48$
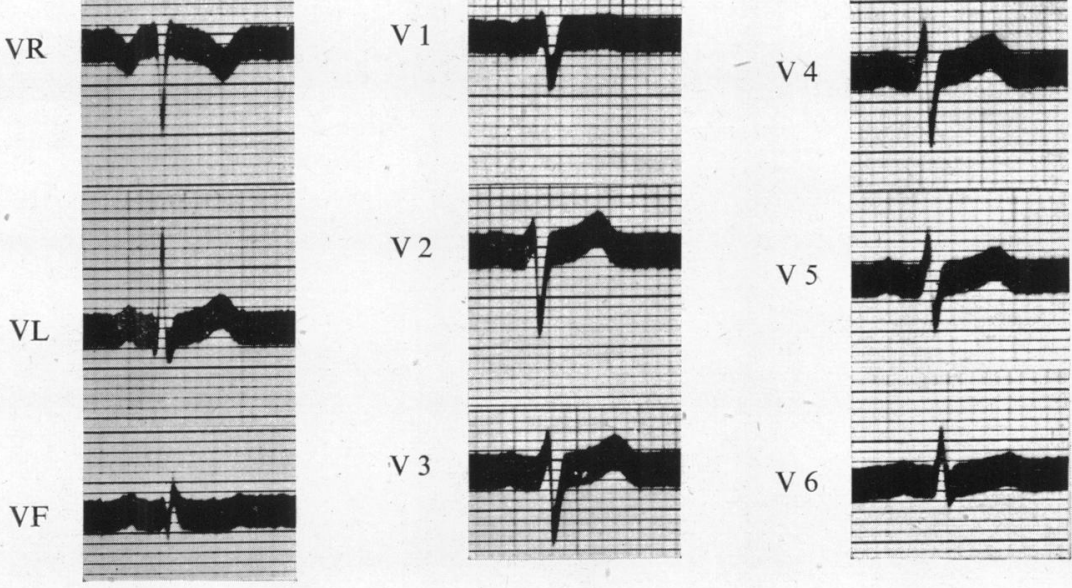

B

Fig. 7.-Case 6. An example of inversion of $T 1$, and $T 2$, but with $T$ 4F remaining upright. The record reverted to normal within three months. (A) Standard leads and lead 4F showing deterioration and recovery. (B) Final unipolar leads $(\mathrm{N} / 2)$. 
and was then described as "constricted breathing," more a discomfort than pain.

There were no abnormal physical signs, B.P. $130 / 80$, and cardioscopy was normal. His cardiogram taken the same day showed only a little left axis deviation. He remained well until 4/8/46 when a second similar attack occurred suddenly at 2 a.m. and lasted for several hours.

A record taken on $8 / 8 / 46$ revealed that now $\mathrm{T} 1$ and $\mathrm{T} 2$ were both inverted, and although $\mathrm{T} 4 \mathrm{~F}$ was not of good amplitude it was still upright. Within eighteen days $\mathrm{T} 1 \mathrm{had}$ improved and become flat and T 2 was upright. By 5/11/46 the curves were normal, and when the patient was last seen on 20/4/48 he was keeping quite free from pain and leading an active life. His cardiogram was still quite normal in standard leads, $4 \mathrm{~F}$, unipolar limb, and præcordial leads.

Comment. An example of cardiac pain at rest, at first accompanied by a normal cardiogram and later by one in which T 1 and $T 2$ became inverted and yet $\mathrm{T} 4 \mathrm{~F}$ remained upright. Within three months of the first abnormal cardiogram, his record had become normal. Here again, it would have been erroneous to assume that his normal cardiogram ruled out the possibility of his pain being cardiac in origin.

Case 7 (Fig. 8). Woman, aged 53. This woman had four quite severe attacks of cardiac pain, all coming on whilst she was at rest. The first attack woke her during the night of $8 / 9 / 47$ and there was such severe substernal pain and dyspnœa that she thought she was going to die. The pain radiated down the left arm into the left middle finger. When seen next day the only abnormal sign was her blood pressure of 180/110. The second attack occurred at 6 a.m. on 11/9/47, was similar to the first and accompanied by much sweating, a pulse rate of 156 , and a temperature of 99 . The next day, 12/9/47, her cardiogram was taken (standard leads, V1, V4, VF, and VL) and was normal. White cell count on $13 / 9 / 47$ was 5000 per c.mm. with a normal differential. B.S.R. on $16 / 9 / 47$ was $12 \mathrm{~mm}$. in the first hour (Westergren).

On 25/9/47 a third attack occurred. She had a little pain in her chest during the day and this suddenly increased and became intense and radiated down the left arm to the wrist. She felt hot and frightened. During the attack her blood pressure was $160 / 100$ but next day had fallen to $120 / 98$. A record taken on $26 / 9 / 47$, the day following the third attack of pain, showed that the RS-T junction and segment in leads 1, 2, and V4 was raised and in leads 1 and 2 it incorporated the $\mathrm{T}$ waves. In $\mathrm{V} 4$ the $\mathrm{T}$ wave was inverted. The segment elevation was about $1 \mathrm{~mm}$. in leads 1 and 2 and was considered consistent with anterior infarction, notwithstanding the facts that her white cell count taken the day after the attack was normal, 8.4 thousand, and her B.S.R. taken on 29/9/47 was $7 \mathrm{~mm}$. in the first hour (Westergren).

By 15/10/47 no further attacks had occurred and the RS-T segment had gone back to the isoelectric level and, as we expected, T 1 and T 2 had become inverted in addition to $\mathrm{T}$ in V4. T 3 had also

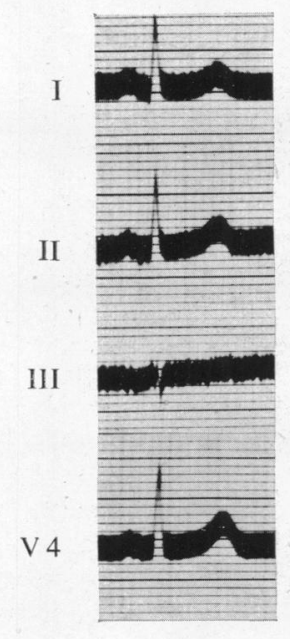

$12 / 9 / 47$

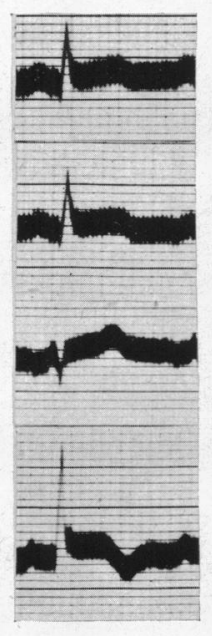

26/9/47

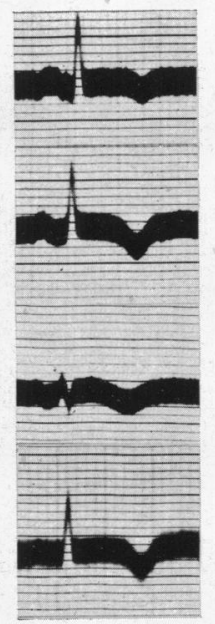

$15 / 10 / 47$

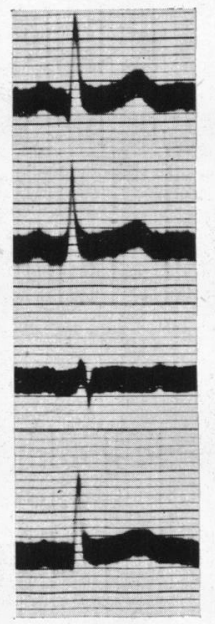

$7 / 11 / 47$

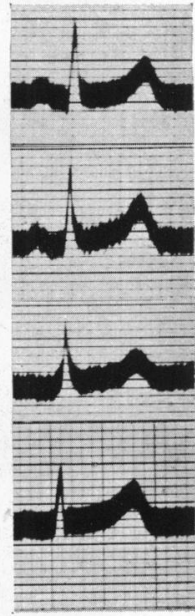

$1 / 5 / 48$

FIG. 8.-Case 7. One of the two records in the series which showed appreciable RS-T segment displacement $(26 / 9 / 47)$. It disappeared in less than three weeks. 
become inverted and this was thought to indicate an extension of the lesion. By 21/10/47 the curves had become quite normal and were repeated on $7 / 11 / 47$ when they were still normal. A fourth attack of pain, felt as a constriction beneath the upper part of the sternum and radiating down the left arm to the elbow, occurred on $21 / 4 / 48$, but a cardiogram taken on $1 / 5 / 48$ which included standard leads, unipolar limb and præcordial leads, was still quite normal.

Comment. There are several reasons for presenting this case. It is one of only two cases in which we have been able to detect segment displacement, although this was only slight. Secondly, it again illustrates how it was not until three attacks of cardiac pain had occurred that any alteration in the cardiogram was detected. In spite of apparent extension of the lesion the cardiogram became normal within three weeks, and in spite of the fourth attack of pain, it remained normal.

Case 8 (Fig. 9). Woman, aged 54. This patient had a six weeks history of " indigestion" when first seen, which during the latter five weeks had been felt as a "terrible dull boring pain" beneath the lower sternum, going up into both jaws and down to both elbows. Without trinitrin the pain lasted twenty minutes. It came on with exertion and caused her to stop walking, an exercise of which she was previously very fond, and it also awakened her.

On examination on 5/12/47 her B.P. was $200 / 140$ and a very clear presystolic gallop rhythm was visible, palpable and audible. A cardiogram taken the same day showed negative $T$ waves in leads $I$, V1, V3, V4, V5, V6, and CF 4. T 2 was flat. No $\mathrm{Q}$ waves were present. These changes were consistent with antero-lateral infarction and hypertensive heart disease. Whilst she was in bed several more attacks of pain occurred and repeated B.S.R. estimations and white cell counts were made during and between these attacks. The highest B.S.R. was $10 \mathrm{~mm}$. in one hour and the highest white cell count was 11.7 thousand per c.mm. with a normal differential count.

Cautiously, the effect on the cardiogram of exercise, of chewing trinitrin tablets, injections of tetraethyl ammonium bromide, and finally of inhaling 5 minims of amyl nitrite was observed. All except the last were without appreciable effect on her cardiogram. The result of amyl nitrite on $30 / 12 / 47$ was striking. The previously inverted $T 1$ and T 2 became upright and T CF 4 was appreciably less inverted. Five hours later the cardiogram had regained its former pathological appearance.

By $2 / 4 / 48$ all signs of infarction change had disappeared and only those due to left ventricular preponderance remained, the inverted $T$ waves in

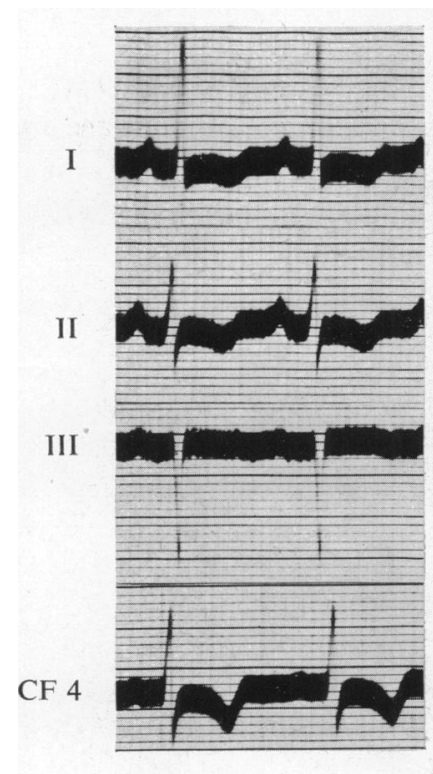

A

Before amyl nitrite

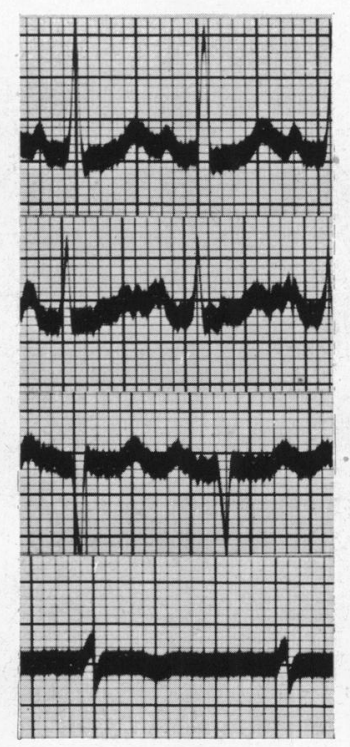

B

During amyl nitrite

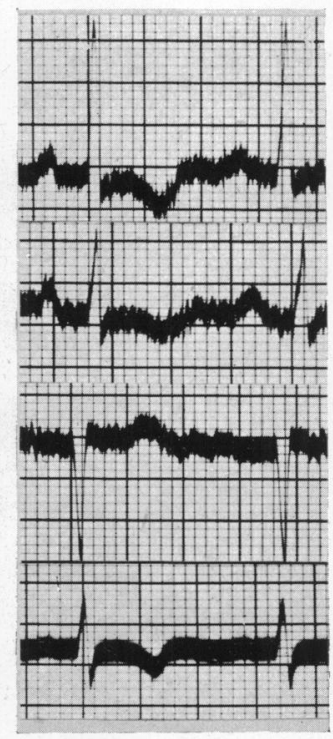

C

5 hrs. after amyl nitrite

FIG. 9.-Case 8. Showing how by inhalation of amyl nitrite it was possible temporarily to elevate inverted $T$ waves in leads I and II. 
lead II having tecome upright and the deeply inverted $\mathrm{T}$ waves in V2-6 inclusive having all disappeared.

Comment. Severely incapacitating cardiac pain, both on effort and at rest, at first was accompanied by cardiographic changes of hypertensive heart disease and later by changes suggesting an extensive area of infarction, but without $Q$ waves. By inhalation of amyl nitrite it was possible temporarily to cause elevation of the $\mathrm{T}$ waves in the standard leads. During the inhalation of amyl nitrite there was an increase in the heart rate, but this was no greater than had previously been produced by exercise without causing any alteration in the $T$ waves.

Case 9 (Fig. 10). Man, aged 50. About the middle of February 1939 the patient began to experience attacks of severe pain just to the left of the sternum, passing down both arms. It came both on exercise and whilst he was asleep in bed. During each attack he became pale and a little cyanosed and was obviously in pain. The duration of each attack varied from half an hour to two hours forty minutes and the pain was best relieved by amyl nitrite. Between attacks he felt perfectly well, there was no dyspnœa, and his B.P. ranged from $130 / 86$ to $140 / 96$; on several occasions it was found to be raised immediately preceding an attack of pain, $160 / 110$ to 186/120.

A teleradiogram revealed slight enlargement of the left ventricle with some elongation of the aorta. The first cardiogram taken on $10 / 3 / 39$, two days after a very severe and prolonged attack of pain, showed T 4R to be sharply inverted, although no $\mathrm{Q}$ waves were present. $\mathrm{T} 1$ was possibly a little low though T 2 was of good amplitude. A second record taken on $13 / 3 / 39$, the patient having remained free from pain since his attack on $8 / 3 / 39$, showed that T 4R had become quite upright. Records repeated on $14 / 3 / 39$ and $27 / 3 / 39$ showed $T 1$ and $T 4$ to be still upright.

Further attacks of pain occurred on $8 / 4 / 39$, $11 / 4 / 39$, and $13 / 4 / 39$, and a record taken on $14 / 4 / 39$ revealed that $\mathrm{T} 4$ had again become deeply inverted and that $\mathrm{T} 1$ had now become inverted for the first time.

He remained free from pain until $20 / 4 / 39$, on which day a very severe attack occurred lasting two hours forty minutes and accompanied by pallor, sweating, and tic-tac rhythm. We obtained a record within a quarter of an hour of the start of this attack and it was normal, T 1 and $\mathrm{T} 4$ having become upright since the previous record. We repeated his cardiogram on the day following the attack and $\mathrm{T} 1$

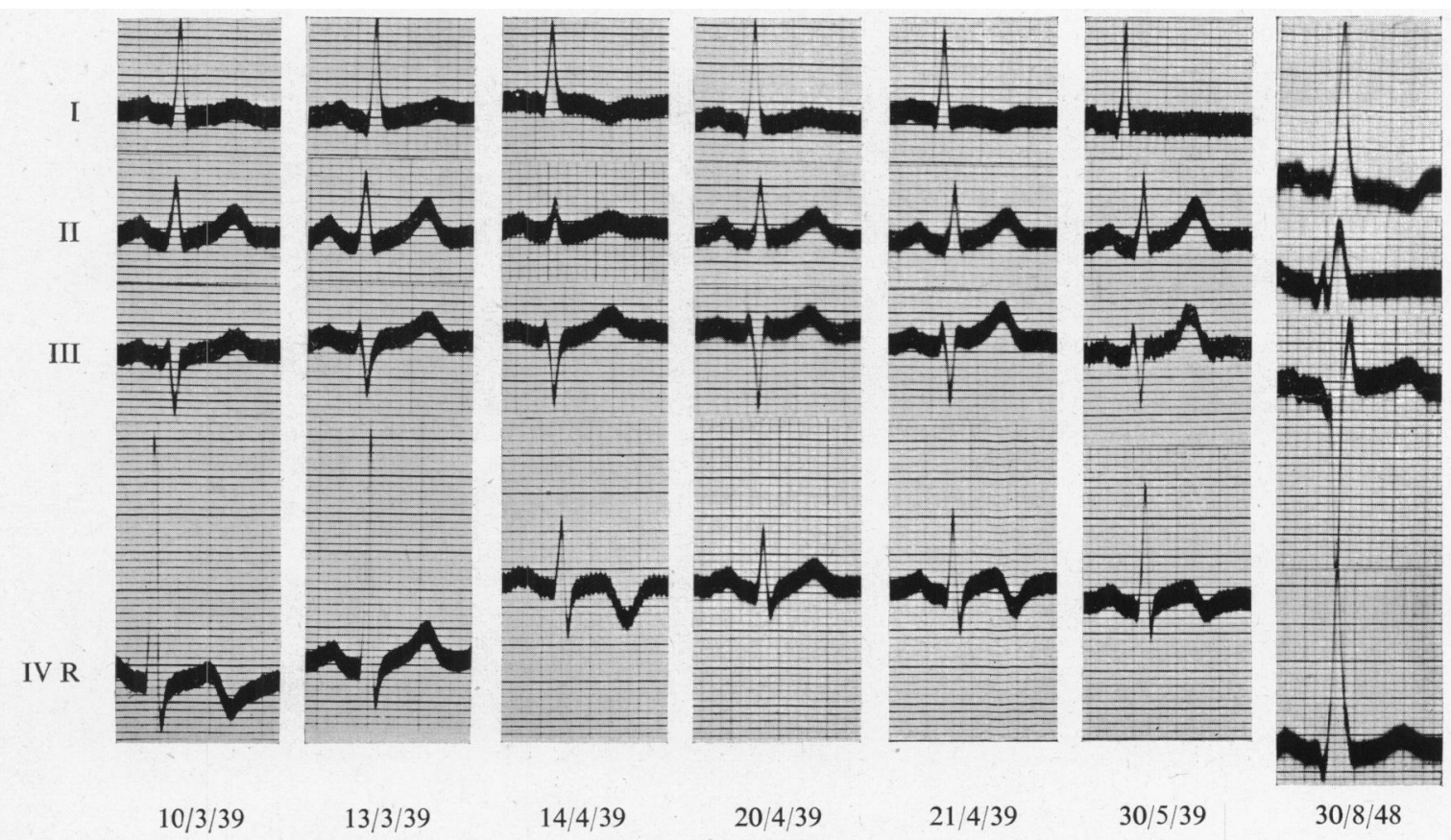

FIG. 10.-Case 9. Showing deterioration and improvement of cardiogram, of rapid sequence, until finally deterioration persists. This suggests that a transient myocardial defect, at first reversible, finally became established. 
and $\mathrm{T} 4$ were then found to have become inverted once more, and the appearance of the RS-T segment in $4 R$ was strongly reminiscent of a recent current of injury curve. From that time on the curves remained abnormal. For example, a record was taken each day from $22 / 4 / 39$ to $28 / 4 / 39$, and on various dates until $30 / 5 / 39$. On $23 / 4 / 39$ half-hourly records were taken from 7 a.m. to 12.30 p.m., covering a period in which the patient was in pain and during which the pain wore off, but all records show the same inversion of the $T$ waves.

It was at that time considered that the change had probably become permanent although the $Q$ waves were insignificant. When seen again on 30/8/48 he stated he had remained free from pain since the middle of 1939, but that his breathlessness on exertion had lately become worse, and attacks of nocturnal dyspnoa were now occurring. His B.P. had fallen to $130 / 80$, and although $T$ in IVR had become upright a wide $Q$ of $2 \mathrm{~mm}$. depth had appeared in this lead, and T 2 had become flat (Fig. 10).

Comment. The records strongly suggest that a transient myocardial lesion, at first reversible, finally became established. Again the cardiographic deterioration lagged considerably behind the patient's pain.

Case 10 (Fig. 11). Man, aged 63. This was a case of hypertensive heart disease. On admission to hospital his B.P. was 195/115 and his rhythm, confirmed by cardiogram on $30 / 12 / 47$, was normal, the curve showing only signs of left ventricular hypertrophy. Transurethral resection of the prostate was performed on $2 / 1 / 48$, and the following day the patient complained of extremely severe burning pain in the chest and back. He was pale and sweating, and auricular fibrillation was present. The blood pressure had fallen to $110 / 80$ and many pulmonary crepitations were audible. The pain lasted several hours and we obtained a cardiogram during the attack. This confirmed the presence of auricular fibrillation and lead CF 4 showed the $\mathrm{T}$ wave to be upright in some beats and inverted, occasionally sharply so, in others. At times an upright $\mathrm{T}$ wave alternated with an inverted one. The QRS deflection did not show this alternation.

$\mathrm{He}$ was immediately given digitalis and also oxygen and papaverine. By the next day he had regained normal rhythm and this persisted. A record taken on $5 / 1 / 48$ confirmed the presence of normal rhythm, and by that time the $T$ waves in CF 4 showed the effect of digitalis only and were all of similar form and amplitude. At the time of his discharge from hospital his B.P. was 200/105.

Comment. Sudden severe pain associated with much shock and transient fibrillation occurred on the day following prostatectomy. During this severe pain the $T$ waves in CF 4 showed alternation which had disappeared two days later when normal rhythm had reappeared. No Q waves were present. The only other case we could find illustrated with alternation of the $T$ wave from upright to inverted, in that case in lead III only, is the one recorded by Hamburger, Katz, and Saphir (1936). Their patient, a woman aged 48 , suffered from anginal attacks and at autopsy small multiple recent and organizing infarcts were present.

\section{Discussion}

The problem is to determine the nature of the underlying pathological state that gives rise to the cardiographic changes described. Any attempt to solve it must be largely conjectural, as the condition is of such good prognosis that it rarely presents an opportunity for autopsy.

Inversion of the $T$ wave can occur in the apparently normal subject, as White (1945) has pointed out. We therefore first considered whether perhaps some of our cases might be accounted for in this way, although the presence of cardiac pain, and the frequently associated hypertension, can scarcely be considered as incidental findings. Graybiel et al. (1944) in an analysis of 1000 healthy young aviators, could find no example of inversion of $T$ in leads $I$ or IV. However, Johnson (1940) during periodic

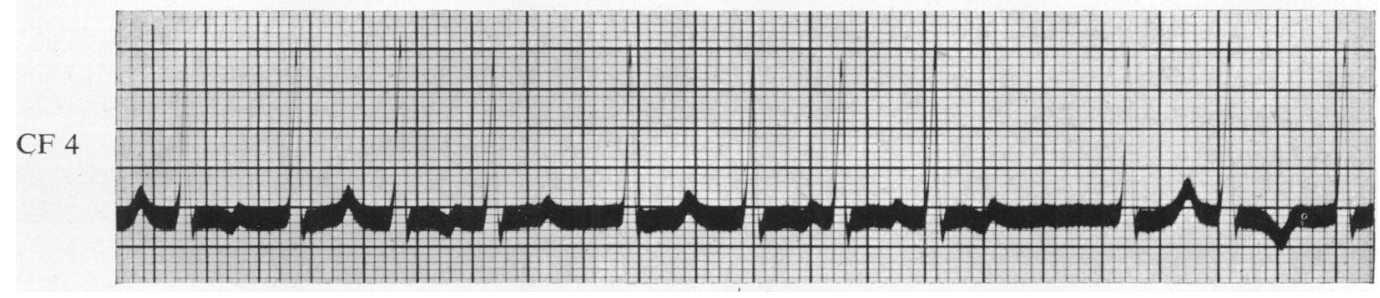

Fig. 11.-Case 10. Lead CF 4 recorded during an attack of cardiac pain. The $T$ wave shows at times alternation, and varies from being sharply upright to being deeply inverted from beat to beat. No $Q$ waves are seen. Auricular fibrillation is present. 
routine examinations of 2400 apparently healthy males of average age 48 years, found that 1 per cent had an inverted or diphasic T 1 and T 2, but only standard leads were employed and the degree of inversion is not stated. Hall et al. (1942) using the three standard leads discovered among the cardiograms of $\mathbf{2 0 0 0}$ members of the Royal Canadian Air Force who were fit for air crew, only two records $(0.1$ per cent) in which $\mathrm{T} 1$ was negative and considered abnormal. In a study of 4810 soldiers, mostly psycho-neurotic, Stein (1946) could find only four $(0 \cdot 1$ per cent) of them with inversion of $T 1$ and $\mathrm{T} 4$ and in three of these the $\mathrm{T}$ inversion disappeared after exercise. Plooij (1946) states emphatically, as a result of his investigation of functional variations of the $\mathrm{T}$ wave, that $\mathrm{T} 1$ is never inverted in health. The conclusions of Graybiel and White (1935) are similar. It would therefore seem reasonable to conclude that the $T$ wave changes in our cases were all of pathological origin.

Considerable evidence has accumulated that reflexes originating elsewhere than in the heart, in particular in the alimentary tract, can cause cardiographic changes strongly reminiscent of cardiac infarction. It is well known that, clinically, disease of the gall bladder, peptic ulcer, and hiatus hernia of the stomach can all produce symptoms that simulate angina pectoris. It has been suggested that such diseases can be responsible per se for changes in the cardiogram that resemble those of myocardial infarction. Clarke (1945) has shewn that the cardiogram may return to normal after the cure of a duodenal ulcer or of cholecystitis, and Brown (1946) and Fitz-Hugh and Wolferth (1935) quote similar cases. Morrison and Swalm (1940) showed how, by dilating the esophagus and stomach of a patient suffering from angina pectoris, changes in the cardiogram could be produced, but this included depression of the RS-T segment in lead 1. But the cardiographic changes as illustrated are minimal and could scarcely be confused with our records. In addition, to the best of our knowledge none of our patients had disease of the alimentary tract. The conclusion is that there is no reason on clinical grounds to suppose that the abnormal changes in our cases are due to derangement in the coronary circulation as a result of reflexes originating from lesions in the alimentary tract or elsewhere.

Of recent years the term " coronary insufficiency" is used to explain abnormality in the cardiogram that may be associated with cardiac pain. The pain can be induced by creating artificially a state of general cardiac anoxia, and the associated changes in the form of the cardiogram are used by Master (1946) and by Levy and his associates (1938, 1940, $1941,1942)$ as an index of the functional efficiency of the heart. Levy insists on the importance of deviation of the RS-T segment. In a later paper, Patterson, Clarke, and Levy (1942) emphasized how the incidence of significant changes in the $T$ wave increases with the degree of total RS-T deviation. The records so obtained do not resemble ours.

It would seem then that our records are not a normal variant, neither are they the result of reflexes arising from disease outside the heart, nor are they due to general cardiac anoxia. Some local abnormality in the myocardium, of a temporary and reversible nature, is likely to be present. Recently we have encountered two cases that throw some light on the problem.

The first patient, a woman aged 41 , under the care of Dr. Clifford Hoyle, suffering from polyarteritis nodosa, complained of retrosternal pain during the night and her cardiogram next day showed that $T 1$, T 2 and T V4 were inverted and yet no $Q$ waves were present (Fig. 12). At autopsy there was no infarct, but three small nodules were found at the tip of the front of the left ventricle. On microscopy these were confirmed to be due to polyarteritis nodosa, and many of the larger branches of the coronary arteries were also involved in that disease. The second case was a man, aged 56, with a blood pressure of $180 / 100$, who had been suffering from very severe cardiac pain, both at rest and on exertion and only of three months' duration. The attacks of pain never lasted more than four minutes. His cardiogram, less than two days before he died, showed inversion of T $1, T 2$ and T VL and T V2-6 inclusive, but with no $Q$ waves present (Fig. 13). Yet at autopsy not only were his coronary arteries quite free from atheroma, but the muscle of the heart was quite normal to close naked eye scrutiny and to minute section of it. There was nothing pathological in the microscopical section, from the right and left ventricle and the septum.

It is possible therefore to have cardiac pain accompanied by cardiographic changes suggesting infarction, but without $Q$ waves, where, in fact, local pathological changes other than infarction are present. Sometimes with these curves no naked eye disease whatsoever is present, and yet the patient may succumb. For many years the occasional absence of pathological changes in the myocardium in some patients who have died of angina pectoris has attracted the attention of clinicians, even to the extent of giving rise to Allbutt's theory that the pain was the "cry of a diseased aorta." The abnormal curves in this type of case show that the myocardium may be at fault even though no sign of disease can be detected at autopsy.

It has, of course, been known for twenty years that a cardiogram taken during and shortly after 


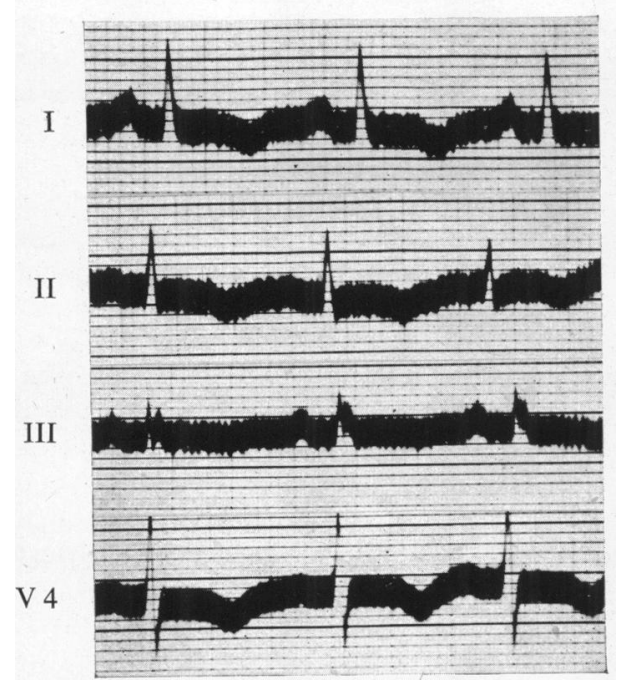

FIG. 12.-Cardiogram from a woman aged 41 who died of polyarteritis nodosa. At the front of the tip of the left ventricle there were several small nodules present which section revealed to be due to polyarteritis nodosa. No infarct was present.

anginal attacks, may show certain transient changes. Feil and Siegel (1928) presented such records in four cases where cardiac infarction could be excluded, and in three of these they recorded a depression of the RS-T segment in leads 1 and 2 during the pain and a return to normal after the pain had ceased. Shortly afterwards, Parkinson and Bedford (1931), employing standard leads, investigated five patients in none of whom was there any question of cardiac infarction at the time the records were taken, and in all five, during the pain the RS-T segment elevation or depression was noted. In four, the cardiogram had reverted to normal within forty minutes, and although the time taken for the fifth one to revert is not stated, it was normal by the time the attack of pain had ceased. On the other hand, Kahn (1931) studied the cardiograms of 330 cases of angina pectoris and observed that 8 of the 23 fatal cases died with no abnormality in the cardiogram, while they were suffering from repeated severe attacks. Emphasis on the characteristic RS-T segment shift was reiterated by Riseman et al. (1940). In a paper devoted to the study of 20 patients with angina, before, during, and after the attacks, they stated that the changes were most frequent and most striking in the præcordial leads, for in these, in all 20 cases, the RS-T segment was deviated. They were of the opinion that only later, towards the end of an attack and also after the disappearance of the pain, did the $\mathrm{T}$ wave changes become pronounced. Wilson and Johnson (1941) studied in detail cardiographic

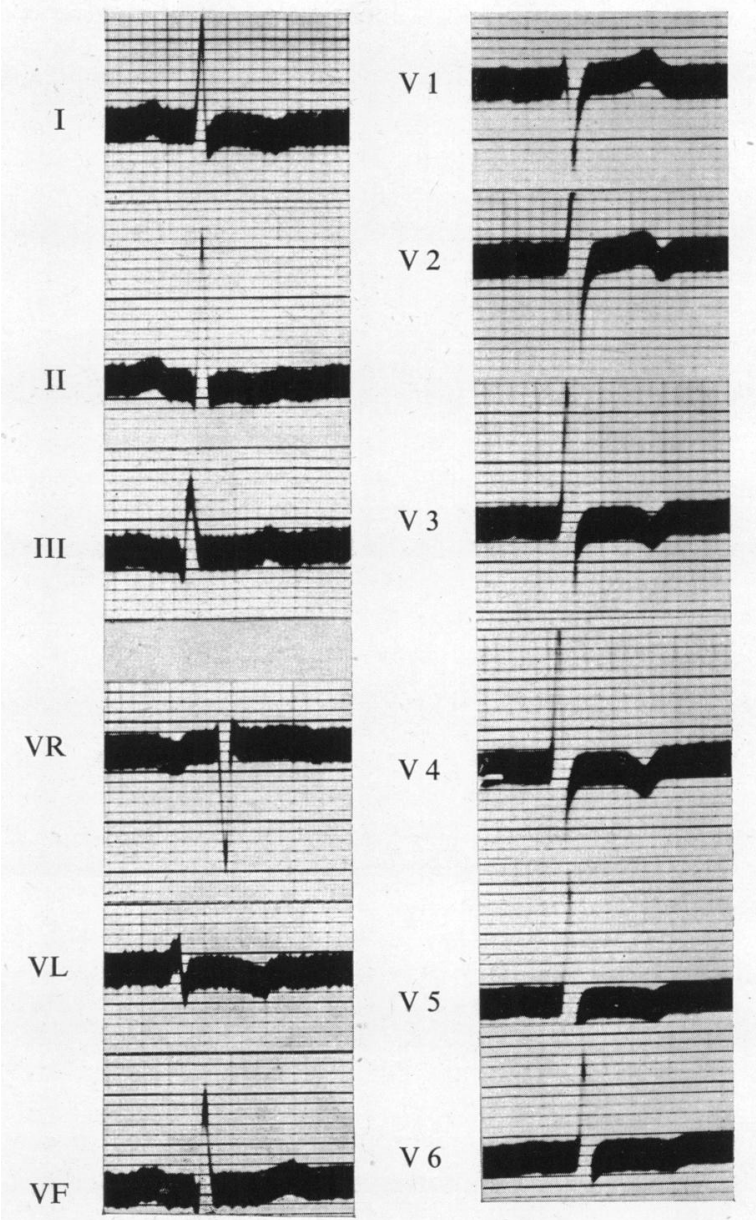

FIG. 13.-Record from a man aged 56 suffering from severe, but very short, attacks of cardiac pain. The cardiogram was taken less than two days before he suddenly died during a paroxysm of pain. At autopsy the heart and coronary vessels were quite normal, both to naked eye and microscopical examination.

changes obtained during the paroxysms of substernal distress, either spontaneous or induced by exercise or cigarette smoking, in five cases of angina pectoris, and in all five there was displacement of the RS-T segment.

It would seem then that the abnormal features shown by our cases are not simply those of the late stages of angina pectoris, as the segment shift was absent or negligible, the duration of the cardiographic changes was much longer, and many of our cases had prolonged pain at rest.

Coming nearer to infarction itself, Feil (1937) thought that he could distinguish a type of pain that precedes coronary thrombosis, but this pain 
does not resemble that experienced by our patients and neither do the cardiograms he obtained whilst they had this pain resemble ours. Although Sampson and Eliaser (1937) also considered that it is possible to diagnose impending acute coronary occlusion, they gave no cardiographic details.

Once an infarct has occurred, provided that enough cardiac muscle has died, there is good experimental evidence, as produced by Wilson $e t$ al. (1933) in dogs, to show that a $Q$ wave will be present. This suggests that in our cases not much muscle, if any, could have died. Certainly, in Case 10 of our series (Fig. 11) in which the $T$ wave in CF 4 varied so much from beat to beat, it is difficult to see how this could result from other than temporary metabolic disturbances. Perhaps the clue to the lesion lies in the work of Bayley and his associates. As a result of experimental work on dogs; Bayley and La Due (1944) state that the electrical phenomena resulting from occlusion of the anterior descending branch of the left coronary artery are entirely independent of demonstrable pathological changes, and that the ischæmia injury changes, though often associated with infarction in man, are not to be regarded as necessarily diagnostic of infarction. In another paper, Bayley, La Due, and York (1944) used a unipolar lead in contact with the anterior surface of the pericardial sac and caused sudden complete occlusion of a dog's coronary artery, short of producing an infarct. They concluded that, contrary to the common belief, the first stage in the cardiographic evolution of myocardial infarct is the appearance of primary $\mathrm{T}$ wave changes which are ascribed to local ventricular ischæmia. In man, Bayley and Monte (1943) encountered a unique case. A hypertensive man experienced cardiac pain while at rest and was considered, by estimating the areas under curve $\mathrm{QRS}$ and under curve $\mathrm{T}$ and calculating $\widehat{A} \mathrm{QRS}, \hat{\mathrm{A}} \mathrm{T}$, and $\hat{\mathrm{A}} \mathrm{QRS}-\mathrm{T}$, to show a severe degree of ischæmia in the distribution of the right coronary artery. This area diminished later and at autopsy the acute ischæmia was seen to have resulted from a dissecting aneurysm involving this artery. No cardiac lesion, naked eye or microscopic, was present. They concluded that " acute left ventricular ischæmia of sufficient intensity to produce striking $T$ wave changes of a kind similar to those that occur in man with myocardial infarction, and lasting for days or even weeks, may be accompanied by no structural changes in the myocardium." They also call attention to the independent variation in magnitude and duration of acute local ischæmia, on the one hand, and pain on the other. It is not yet known how long local ischæmia, associated with only primary $\mathrm{T}$ wave changes, must exist in order to be followed by local myocardial fibrosis.
We conclude, therefore, that in our cases the presence of what we regard as primary $T$ wave changes are the result of ischæmia of the myocardium caused by spasm of the coronary arteries. We have noted also the absence of displacement of the RS-T segment and the absence of $Q$ waves. The reduction in the calibre of the vessel is not sufficient in degree or duration to lead to death of the myocardial fibres and subsequent fibrosis, or, if it does so, to anything but the slightest extent. The essential thing is coronary spasm; coronary atheroma is not a necessary feature. We do not know what causes such spasm nor why the left coronary artery should be involved so much more frequently than the right. Lisa and McPeak (1940) believe that coronary spasm without atheroma can lead to what they term " acute miliary infarction," and that infection is the precipitating cause of the spasm. Although their histological findings bear a striking resemblance to those seen in our Case 1, infection was not a feature of our cases, except possibly in Case 6.

\section{SumMary}

When patients thought to be suffering from cardiac infarction were followed up, a small proportion of them were found in whom the cardiogram returned to normal and remained so. Most of these patients were hypertensive, and in more than half of them the attacks of pain ceased though the hypertension persisted.

If the cardiogram of such patients is compared with that of indisputable infarction, it will be found that almost all of them are anterior in distribution, that the $Q$ waves are absent or insignificant, and that, with very few exceptions, there is no current of injury however early the record is taken. On the other hand, we do not claim that a patient yielding such a curve as we have described, but not returning to normal, has necessarily a good prognosis ; and we give an example where such a patient died suddenly, autopsy revealing no abnormality whatsoever. The term " recovery of the T wave" does not necessarily imply recovery of the patient, although the prognosis in the group as a whole is surprisingly good.

It is, of course, well known that the majority of patients who experience cardiac pain that comes on at rest and lasts for, say, more than half an hour, will have an abnormal cardiogram. But we would draw attention to the error of assuming that a patient with such pain, but with a normal cardiogram, cannot be suffering from cardiac pain. Several of our cases had pain that was at first, and on more than one occasion, accompanied by a normal 
record, which only later showed the expected pathological changes. We suggest that prolonged spasm of the coronary artery is responsible for the cardiographic appearance, and only if the spasm is of sufficiently long duration does any fibrosis result, and this is minimal.

Since submitting this paper we have encountered six further cases; five were anterior and one posterior.

\section{REFERENCES}

Bayley, R. H., and La Due, J. S. (1944). Amer. Heart J., 28, 54 .

-1, and York, D. J. (1944). Ibid., 27, 657.

- and Monte, L. A. (1943). Ibid., 25, 262.

Brown, H. (1946). Clin. Proc., 5, 447.

Clarke, N. E. (1945). Amer. Heart J., 29, 628.

Feil, H. (1937). Amer. J. med. Sci., 193, 42.

, and Siegel, M. L. (1928). Ibid., 175, 255.

Fitz-Hugh, T., and Wolferth, C. C. (1935). Ann. Surg., $101,478$.

Graybiel, A., McFarland, R. A., Gates, D. C., and Webster, F. A. (1944). Amer. Heart J., 27, 524. and White, P. D. (1935). Ibid., 10, 345.

Hall, G. E., Stewart, C. B., and Manning, G. W. (1942). Canad. med. Ass. J., 46, 226.

Hamburger, W. W., Katz, L. N., and Saphir, O. (1936). J. Amer. med. Ass., 106, 902.

Johnson, H. J. (1940). Ibid., 114, 561.

Kahn, M. H. (1931). Ann. intern. Med., 4, 1499.

Lenègre, J., and Chevalier, H. (1946). Arch. Mal. Coeur, 39, 37.

Levy, R. L. (1938). Amer. Heart J., 15, 187.
Levy, R. L. (1941). Bull. N.Y. Acad. Med., 17, 898. Bruenn, H. G., and Williams, N. E. (1940). Amer. Heart J., 19, 639.

Lisa J. R., and McPeak, E. (1940). Arch. intern. Med., $65,919$.

Master, A. M. (1946). New York Med., 2, 19.

Morrison, L. M., and Swalm, W. A. (1940). J. Amer. med. Ass., 114, 217.

Parkinson, J., and Bedford, D. E. (1931). Lancet, 1, 15.

Patterson, J. E., Clark, T. W., and Levy, R. L. (1942). Amer. Heart J., 23, 837

Plooij, M. (1946). Arch. Mal. Coeur, 39, 126.

Riseman, J. E. F., Waller, J. V., and Brown, M. G. (1940). Amer. Heart J., 19, 683.

Sampson, J. J., and Eliaser, M. (1937). Ibid., 13, 675.

Stein, I. (1946). J. Lab. clin. Med., 31, 837.

Wilson, F. N., and Johnston, F. D. (1941). Amer. Heart J., 22, 64.

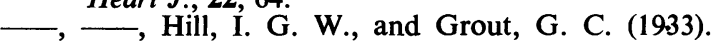
Trans. Ass. Amer. Phys., 48, 154.

White, P. D. (1945). Heart Disease, 3rd ed., New York, p. 207 